\title{
Mono Fetal Demise in Twin Gestation and Outcome
}

\author{
${ }^{1}$ TP Sinduja, ${ }^{2}$ Nazira Sadique, ${ }^{3}$ Pavithra
}

\begin{abstract}
We present two cases of dichorionic diamniotic (DCDA) twin and one monochorionic diamniotic (MCDA) twin during their third trimester with single intrauterine fetal demise (IUFD) and their outcomes. These cases were not found to be associated with any of the high-risk factor for fetal demise in twin like abruption placenta, velamentous insertion of cord or cord entanglement. ${ }^{1}$ Between the DCDA twins, one case developed coagulation disorder, the other case developed acute fatty liver of pregnancy after 2 weeks of diagnosing IUFD and emergency termination was done. Whereas the MCDA twin showed, hypoxic ischemic encephalopathy (HIE) changes in fetal magnetic resonance imaging (MRI) and emergency termination of pregnancy was done.
\end{abstract}

Keywords: Co-twin IUD, CPAP, Fetal hypoxia, Intrauterine fetal demise, Maternal coagulation profile alteration, Neonatal counseling, Neonatal jaundice, Preterm, Respiratory distress, Retinopathy of prematurity, Serum fibrinogen, Steroid coverage.

How to cite this article: Sinduja TP, Sadique N, Pavithra. Mono Fetal Demise in Twin Gestation and Outcome. J South Asian Feder Obst Gynae 2015;7(3):199-201.

Source of support: Nil

Conflict of interest: None

Date of received: 14 September 2015

Date of acceptance: 12 October 2015

Date of publication: December 2015

\section{INTRODUCTION}

Mono fetal demise in multifetal gestation poses high risk for the survivor twin in the forms of varying degrees of cerebral palsy, preterm delivery, intrauterine growth restriction (IUGR), renal agenesis and intestinal obstruction $^{2}$. The incidence of single fetal death in twin pregnancies after 20 weeks is $3.3 \%{ }^{3}$. The extent of damage to the survivor twin and maternal mortality mainly is decided by the chorionicity and the period of gestation. However, the management protocol differs for each case scenario and is a challenge to the obstetrician in deciding the mode

\footnotetext{
${ }^{1}$ Postgraduate, ${ }^{2}$ Additional Professor, ${ }^{3}$ Assistant Professor

${ }^{1-3}$ Department of Obstetrics and Gynecology, Sri Ramachandra Medical College, Porur, Chennai, Tamil Nadu, India

Corresponding Author: TP Sinduja, Postgraduate Department of Obstetrics and Gynecology, Sri Ramachandra Medical College, Porur, M10, Southern Shelters, Katupakkam Chennai-600056, Tamil Nadu, India, email: sinduja.tp@gmail. com
}

and time of delivery. In this review, we summarize the management and outcome of three different cases with single intrauterine fetal demise (IUFD) at varying periods of gestational age and chorionicity with three different reasons for termination is discussed.

\section{CASE REPORTS}

\section{Case 1}

Unbooked gravida two parity one monochorionic diamniotic (MCDA) twin spontaneously conceived with previous lower segment cesarean section (LSCS) was diagnosed to have co-twin demise @28 weeks by ultrasonogram. Corticosteroid coverage was given. Ultrasound and serial serum fibrinogen values were monitored (Table 1). At 32 weeks of gestation lives fetus showed prominent left ventricles with normal Doppler flow of middle cerebral artery in the ultrasonogram. Fetal magnetic resonance imaging (MRI) was done showed features of hypoxic ischemic encephalopathy (HIE) (Figs 1A and B). Neonatologist counseling given about risk involved of having HIE and preterm delivery, consent obtained for the same. Emergency LSCS was done in view of suspected fetal hypoxia. Intraoperative findings twin I delivered by breech with birthweight of $1.1 \mathrm{~kg}$ and Apgar of 6/10, 7/10. Twin II was a macerated fetus with mahogany colored fowl smelling liquor. Postpartum period was uneventful. Baby was admitted in neonatal intensive care unit (NICU) in view of prematurity and required continuous positive airway pressure (CPAP) till day 4 of life. Phototherapy given for hyperbilirubinemia. Ultrasonography cranium showed mild dilated ventricles, and baby was followed for 2 years, milestones were normal.

\section{Case 2}

Unbooked primigravida @29 weeks with dichorionic diamniotic (DCDA) twin conceived spontaneously was admitted in emergency department with scan showing co-twin demise and complaints of pruritus. Ultrasonography showed IUGR features for the surviving twin and macerated fetus with spalding sign to the other twin. Blood investigations revealed elevated alanine transaminase and aspartate transaminase levels and a normal coagulation profile; viral markers were done to rule out viral hepatitis. Serial liver function test was monitored. Multidisciplinary approach was given with 

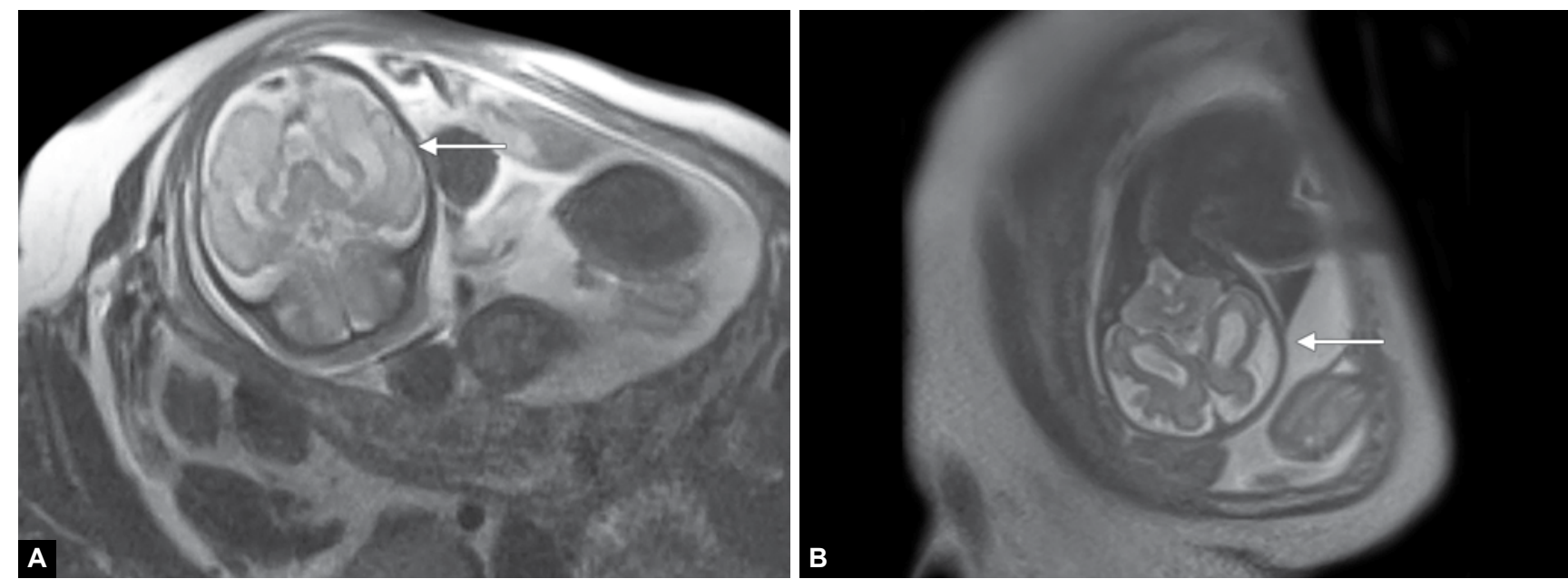

Figs 1A and B: Axial and coronal T2-weighted images of the fetal brain showing dilatation of the bilateral lateral ventricles with severe thinning of the cerebral parenchyma in the occipital region

gastroenterologist and neonatologist support. Steroids coverage done. Liver function test (LFT) value alteration was noted at 32 weeks (Table 1), acute fatty liver of pregnancy was suspected and emergency LSCS done to terminate the pregnancy. Intraoperative twin I was macerated male fetus with weight of $400 \mathrm{gm}$ (Figs 2A and B). Twin II was female baby with birthweight of $1.14 \mathrm{~kg}$ and apgar 7/10,8/10. Postpartum baby developed apnea of prematurity and needed intubation for 2 days, followed by CPAP support for 2 days. Phototherapy was initiated for 3 days in view of hyperbilirubinemia. Diagnosis of retinopathy of prematurity made, and treated accordingly. Normal milestones were achieved. Postoperative maternal serial monitoring of liver function test was done and conservative management followed. Liver function test reverted to normal range in 1 week.

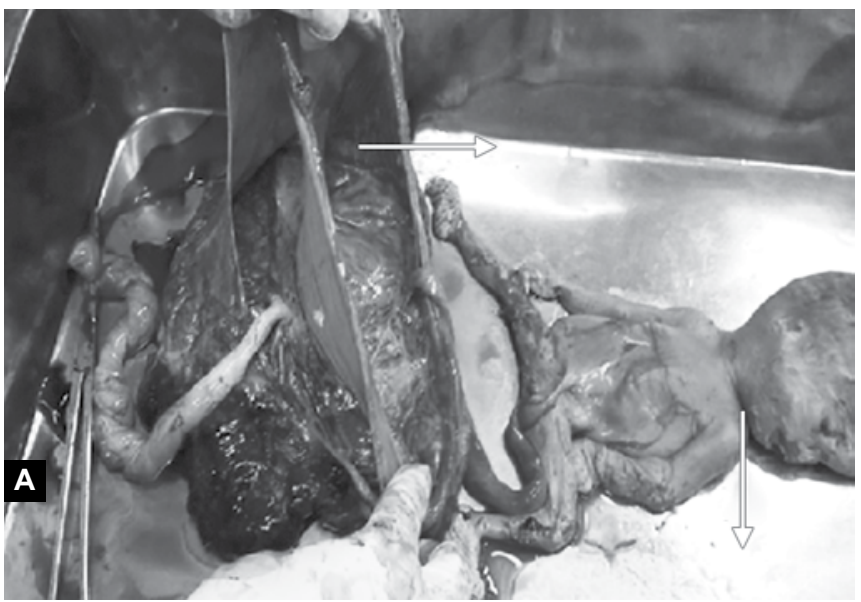

\section{Case 3}

Unbooked primigravida @29 weeks with DCDA twin, referred with scan reports of twin I showing features of intrauterine device (IUD) (Fig. 3). Coagulation profile was repeated weekly, steroids coverage done. Weekly non-stress test (NST) and coagulation profile was done. By 32 weeks +1 day serum fibrinogen values dropped to $175 \mathrm{mg} / \mathrm{dl}$ (Table1).Fiveunits of cryoprecipitatewasarranged and patienttakenupforemergency LSCS. PreoperativetwinI was a baby boy weighing $1.6 \mathrm{~kg}$ with Apgar of 8/10,9/10. Baby was shifted to NICU for respiratory distress and given CPAP support for 3 days, neonatal jaundice was diagnosed. Twin II was a macerated male fetus weighing $750 \mathrm{gm}$. Postoperative period was uneventful and liver function test reverted back to normal range in 1 week. Baby had normal milestones.

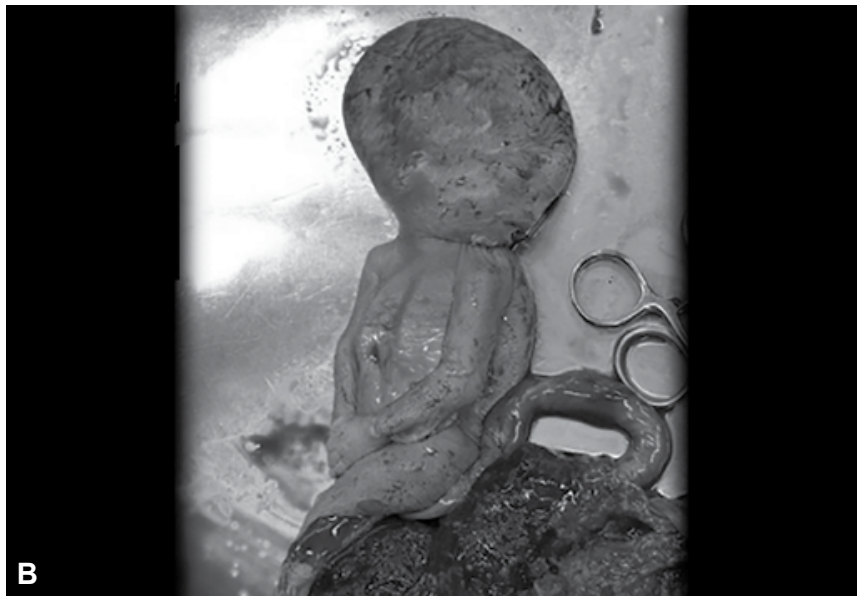

Figs 2A and B: Macerated twin baby with placenta

Table 1: Comparison of lab investigations among the three cases

\begin{tabular}{lllllll}
\hline Cases & Gestational age in weeks & Delivered in weeks & Liver function test & D dimer & Sr fibrinogen & INR \\
\hline 1 & 28 & 32 & Elevated & Normal & 514 & 0.98 \\
2 & 29 & 32 & Normal & Normal & 175 & 0.90 \\
3 & 29 & 32 & Normal & Normal & 275 & 0.97 \\
\hline
\end{tabular}




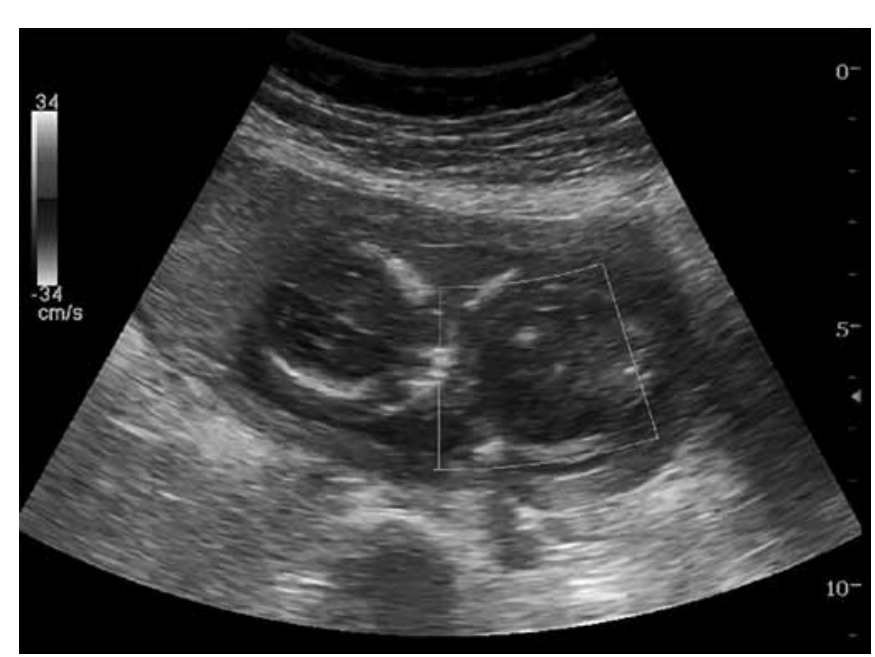

Fig. 3: Antenatal ultrasonogram of 29 weeks with scan showing absent fetal heart rate

\section{DISCUSSION}

The rate of multifile gestation has a recent rise in number due to vast availability of reproductive techniques, this is followed with subsequent risk of sIUFD and other risk of cerebral palsy, congenital abnormalities like neural tube defects, optic nerve hypoplasia, hypoxic ischemic lesions of white matter, microcephaly, posthemorrhagic hydrocephalus, bilateral renal cortical necrosis, unilateral absence of kidney, and gastrointestinal tract atresia for the surviving twin. ${ }^{7}$ Coagulopathy is the most dreaded maternal complication which needs serial monitoring of the maternal coagulation profile and warranting the termination of pregnancy. Following the death of one twin, the risk of neurological abnormality in the surviving monochorionic and dichorionic co-twin was 18 and $1 \%$, respectively. ${ }^{4}$ The risk of preterm delivery was 68 and $57 \%$, respectively. ${ }^{4}$ The odds of monochorionic cotwin intrauterine death was six times that of dichorionic twins; ${ }^{3}$ hence, it is better to determine the risk based on the chorionicity of the twin. However, the greatest risk to the surviving fetus, regardless of chorionicity, is preterm delivery and the associated complications of prematurity, again explaining the need for corticosteroid coverage. Overall, 50 to $80 \%$ of surviving twins are born preterm, most often because of preterm onset of labor. ${ }^{5}$ The mode of delivery is left to the choice of the obstetrician based on the chorionicity, gestation and the extent of complications involved in the surviving twin and the maternal status. ${ }^{6}$ Fetal MRI is needed when suspicious cardiotocography (CTG) reports, ventriculomegaly or microcephaly are suspected in ultrasound. ${ }^{8}$ Neonatal counseling should be arranged and a close discussion between the parents, obstetricians and neonatologist should be followed till the time of delivery.

\section{SUMMARY}

It seems that surviving co-twin prognosis is mainly compromised by prematurity and its consequences, hence, expectant management of single fetal death in twin pregnancies might be advisable under close surveillance of both, mother and the surviving fetus. ${ }^{7}$

\section{REFERENCES}

1. D'Alton ME, Newton ER, Cetrulo CL. Intrauterine fetal demise in multiple gestations. Acta Geneticae Medicae ET Gemellologiae 1984;33(1):43-49.

2. Aslan H, Gul A, Cebeci A, Polat I, Ceylan Y. Twin Res. 2004 Feb;7(1):1-4. PMID: 15053847 [PubMed-indexed for MEDLINE]

3. Stroup DF, Berlin JA, Morton SC, Olkin I, Williamson GD, Rennie D, et al. Meta-analysis of observational studies in epidemiology: a proposal for reporting. Meta-analysis of Observational Studies in Epidemiology (MOOSE) group. JAMA 2000;283(15):2008-2012.

4. DeFalco LM, Sciscione AC, Megerian G, Tolosa J, Macones G, O'Shea A, et al. Inpatient versus outpatient management of monoamniotic twins and outcomes. Am J Perinatol 2006; 23(4):205-211.

5. Heyborne KD, Porreco RP, Garite TJ, Phair K, Abril D. Improved perinatal survival of monoamniotic twins with intensive inpatient monitoring. Am J Obstet Gynecol 2005; 192(1):96-101.

6. Cleary-Goldman J, D'Alton ME. Uncomplicated Monochorionic Diamniotic Twins and the Timing of Delivery. PLoS Med 2005;2(6):e180.

7. Enbom JA. Twin pregnancy with intrauterine death of one twin. Am J Obstet Gynecol 1985;152(4):424-429.

8. Glen OA, Goldstein RB, Li KC, Yung SJ, Norton ME, et al. Magnetic resonance imaging in the evaluation of fetuses referred for sonographically suspected abnormalities of the corpus callosum. J Ultrasound Med 2005;24(6):791-804. 